\title{
MRI Assessment of Complete Response to Preoperative Chemoradiation Therapy for Rectal Cancer: 2020 Guide for Practice from the Korean Society of Abdominal Radiology
}

\author{
Seong Ho Park, MD, $\mathrm{PhD}^{1}$, Seung Hyun Cho, MD, PhD², Sang Hyun Choi, MD, PhD ${ }^{1}$, \\ Jong Keon Jang, MD, $\mathrm{PhD}^{1}$, Min Ju Kim, $\mathrm{MD}^{3}$, Seung Ho Kim, MD, PhD ${ }^{4}$, Joon Seok Lim, MD, PhD ${ }^{5}$, \\ Sung Kyoung Moon, MD, $\mathrm{PhD}^{6}$, Ji Hoon Park, MD, PhD ${ }^{7}$, Nieun Seo, MD, PhD ${ }^{5}$, \\ for the Korean Society of Abdominal Radiology Study Group for Rectal Cancer

\footnotetext{
${ }^{1}$ Department of Radiology and Research Institute of Radiology, University of Ulsan College of Medicine, Asan Medical Center, Seoul, Korea; ${ }^{2}$ Department of Radiology, Kyungpook National University Medical Center, School of Medicine, Kyungpook National University, Daegu, Korea; ${ }^{3}$ Department of Radiology, Ewha Womans University Seoul Hospital, Seoul, Korea; ${ }^{4}$ Department of Radiology, Inje University College of Medicine, Haeundae Paik Hospital, Busan, Korea; ${ }^{5}$ Department of Radiology, Severance Hospital, Yonsei University College of Medicine, Seoul, Korea; ${ }^{6}$ Department of Radiology, Kyung Hee University Hospital, Seoul, Korea; ${ }^{7}$ Department of Radiology, Seoul National University College of Medicine, Seoul National University Bundang Hospital, Seongnam, Korea
}

Objective: To provide an evidence-based guide for the MRI interpretation of complete tumor response after neoadjuvant chemoradiation therapy (CRT) for rectal cancer using visual assessment on T2-weighted imaging (T2) and diffusion-weighted imaging (DWI).

Materials and Methods: PubMed MEDLINE, EMBASE, and Cochrane Library were searched on November 28, 2019 to identify articles on the following issues: 1) sensitivity and specificity of T2 or DWI for diagnosing pathologic complete response (pCR) and the criteria for MRI diagnosis; 2) MRI alone vs. MRI combined with other test(s) in sensitivity and specificity for pCR; and 3) tests to select patients for the watch-and-wait management. Eligible articles were selected according to meticulous criteria and were synthesized.

Results: Of 1615 article candidates, 55 eligible articles (for all three issues combined) were identified. Combined T2 and DWI performed better than T2 alone, with a meta-analytic summary sensitivity of 0.62 (95\% confidence interval [CI], $0.43-$ $\left.0.77 ; \mathrm{I}^{2}=80.60\right)$ and summary specificity of $0.89\left(95 \% \mathrm{CI}, 0.80-0.94 ; \mathrm{I}^{2}=92.61\right)$ for diagnosing $\mathrm{pCR}$. The criteria for the complete response on T2 in most studies had the commonality of remarkable tumor decrease to the absence of mass-like or nodular intermediate signal, although somewhat varied, as follows: (near) normalization of the wall; regular, thin, hypointense scar in the luminal side with (near) normal-appearance or homogeneous intermediate signal in the underlying wall; and hypointense thickening of the wall. The criteria on DWI were the absence of a hyperintense signal at high b-value $(\geq 800$ $\mathrm{sec} / \mathrm{mm}^{2}$ ) in most studies. The specific algorithm to combine T2 and DWI was obscure in half of the studies. MRI combined with endoscopy was the most utilized means to select patients for the watch-and-wait management despite a lack of strong evidence to guide and support a multi-test approach.

Conclusion: This systematic review and meta-analysis provide an evidence-based practical guide for MRI assessment of complete tumor response after CRT for rectal cancer.

Keywords: Rectal cancer; Adenocarcinoma; Chemoradiotherapy; Chemoradiation; Response; Remission; Regression; $C R$; Magnetic resonance imaging; Watch and wait; Wait and see; Organ preservation; Surveillance; Evidence; Guideline; Recommendation

Received: April 18, 2020 Revised: April 18, 2020 Accepted: April 19, 2020

Corresponding author: Seong Ho Park, MD, PhD, Department of Radiology and Research Institute of Radiology, University of Ulsan College of Medicine, Asan Medical Center, 88 Olympic-ro 43-gil, Songpa-gu, Seoul 05505, Korea.

- Tel: (822) 3010-5984•Fax: (822) 476-4719• E-mail: parksh.radiology@gmail.com

This is an Open Access article distributed under the terms of the Creative Commons Attribution Non-Commercial License (https:// creativecommons.org/licenses/by-nc/4.0) which permits unrestricted non-commercial use, distribution, and reproduction in any medium, provided the original work is properly cited. 


\section{INTRODUCTION}

Preoperative neoadjuvant chemoradiation therapy (CRT) is now a standard treatment for rectal cancers with a high risk of recurrence after surgery (1). CRT typically takes 5-6 weeks (long-course therapy), and surgery is generally performed a few months later (1). Within the published literature, $10-25 \%$ of patients achieve pathologic complete response ( $p C R$ ) after CRT, i.e., no residual tumor on pathologic examination $(1,2)$. Evidence from observational studies suggests that patients who are considered to have achieved pCR after CRT could be managed with careful regular surveillance, referred to as the watch-and-wait approach as an alternative to surgery (3-7). This watchand-wait approach may provide an opportunity to avoid surgical complications, perioperative morbidity and mortality, and the need for a permanent stoma. It is critical to carefully determine patients with no clinically apparent residual tumor with a thorough assessment of the treatment response to CRT, as the safety of the watch-and-wait approach is yet uncertain.

Magnetic resonance imaging (MRI) is the imaging of choice in patients with rectal cancer to evaluate the response to CRT, as well as for the initial pretreatment evaluation (7-9). Unlike well-established guidelines on the pretreatment MRI evaluation of rectal cancers (10-15), there is a relative scarcity of guidance for the MRI evaluation of CRT response. Therefore, this study aimed to provide an evidence-based guide from the Korean Society of Abdominal Radiology (KSAR) for the MRI assessment of complete tumor response after CRT for rectal cancer. There is a variety of MRI techniques used for this purpose. Of those, this study addresses visual assessment using T2-weighted imaging (T2) and diffusion-weighted imaging (DWI) because these are the imaging methods that are widely used in the real-world practice at present. Other techniques-including radiomics, texture analysis, modeling using artificial intelligence (such as machine learning or deep learning), quantitative lesion metrics (such as volumetry or sum of the areas by drawing the lesion boundary), quantitative diffusion analysis (such as apparent diffusion coefficient, kurtosis coefficient, and intravoxel incoherent motion parameters), and perfusion analysis by dynamic-contrast enhanced imaging - were not considered as these are mostly still in research territory due to limitations in generalizability, reproducibility, and practicality $(16,17)$. Additionally, this study focuses on the evaluation of the primary tumor site and does not cover other types of tumor spread, such as nodal metastasis and tumor deposits.

\section{MATERIALS AND METHODS}

\section{Literature Database Search}

PubMed MEDLINE, EMBASE, and Cochrane Library were searched to identify articles related to any of the three issues as follows:

- Issue 1: sensitivity and specificity of MRI (T2 or DWI) for diagnosing $\mathrm{pCR}$ and the criteria for the MRI diagnosis

- Issue 2: comparison of MRI alone (T2 with or without DWI) and MRI combined with other test(s) regarding sensitivity and specificity for $\mathrm{pCR}$

- Issue 3: tests used to select patients for the watch-andwait management.

This study developed the search queries according to the PICO method (18) as much as applicable and jointly used hand-searching to enable an exhaustive literature search, as shown in Table 1. Besides the basic search terms, this study also included extra terms that frequently appeared in the relevant articles in the search query in ' $O R^{\prime}$ combination to expand the search (i.e., additional terms regarding $\mathrm{P}, \mathrm{I}$, and $C$ as shown in Table 1 ). The last update of the literature database search was on November 28, 2019. The literature database search covered both print publications and electronic publications ahead of print.

A total of 1615 articles were screened for eligibility, after deleting overlaps between the three databases (Fig. 1). The general criteria for article exclusion were as follows: 1 ) duplicated publications; 2) articles not within the topics of interest of this study; 3 ) not an original research or study protocol (for issue 3 ), such as case reports, review articles, editorials, letters, or comments; 4) articles without the full text available, such as conference abstract/proceedings; and 5) articles written in other languages than English. Articles that had any of these characteristics were excluded. Then, each issue-specific eligibility criteria were applied to further select relevant articles, as explained later in the corresponding sections. The article screening and selection were performed by one of eight authors. In any case, where there was an ambiguity, another reviewer was invited to jointly review the article and arrive at a consensus. The nine authors also performed data extraction from eligible articles for meta-analysis and systematic review in the same manner, i.e., data extraction by one of the eight authors and double-checked by the remaining author to make a 
Table 1. Query for Literature Database Search

\begin{tabular}{|c|c|c|c|c|}
\hline \multirow{2}{*}{ PICO } & \multicolumn{2}{|r|}{ Query for Issues 1 and 2} & \multicolumn{2}{|r|}{ Query for Issue 3} \\
\hline & Search Concept & Search Term & Search Concept & Search Term \\
\hline \multirow{21}{*}{$\begin{array}{l}\text { P: A AND B } \\
\text { AND C }\end{array}$} & A. Patient with & \#1: “Rectal Neoplasms"[Mesh] & A. Patient with & \#1: “Rectal Neoplasms”[Mesh] \\
\hline & rectal cancer: & \#2: (Colorectal[TW] OR Rectal[TW] OR rectum[TW] & rectal cancer: & \#2: (Colorectal[TW] OR Rectal[TW] OR \\
\hline & \#1 OR \#2 & OR Anus[TW]) AND (Neoplasm*[TW] OR & \#1 0R \#2 & rectum[TW] OR Anus[TW]) AND \\
\hline & & neoplasia[TW] OR cancer*[TW] OR tumor* ${ }^{*}$ TW] & & (Neoplasm*[TW] OR neoplasia[TW] \\
\hline & & OR tumour* $[$ TW] OR Carcinoma* [TW] OR & & OR cancer* $[$ TW $]$ OR tumor* $[$ TW] OR \\
\hline & & Malignan*[TW]) & & tumour*[TW] OR Carcinoma* $[$ TW] \\
\hline & & & & OR Malignan*[TW]) \\
\hline & B. Undergoing & \#3: “Chemoradiotherapy"[Mesh] & B. Undergoing & \#3: “Chemoradiotherapy"[Mesh] \\
\hline & chemoradiation & \#4: chemoradiotherap*[TW] OR & chemoradiation & \#4: chemoradiotherap*[TW] OR \\
\hline & therapy: \#3 & chemoradiation* ${ }^{*}$ TW] OR & therapy: \#3 & chemoradiation*[TW] OR \\
\hline & OR \#4 OR \#5 & radiochemotherap* [TW] OR chemo-rad*[TW] & OR \#4 OR \#5 & radiochemotherap*[TW] OR \\
\hline & OR \#6 & OR Radio-Chemo*[TW] OR “CCRT”[TW] OR & OR \#6 & chemo-rad*[TW] OR Radio- \\
\hline & & "CCRTx"[TW] & & Chemo*[TW] OR “CCRT"[TW] OR \\
\hline & & & & "CCRTx" [TW] \\
\hline & & \#5: chemotherap* [TW] AND (radiation therap* [TW] & & \#5: chemotherap*[TW] AND (radiation \\
\hline & & OR Radiotherap*[TW]) & & therap*[TW] OR Radiotherap*[TW]) \\
\hline & & $\begin{array}{l}\text { \#6: “Neoadjuvant Therapy"[Mesh] OR } \\
\text { neoadjuvant*[TW] }\end{array}$ & & $\begin{array}{l}\text { \#6: “Neoadjuvant Therapy"[Mesh] OR } \\
\text { neoadjuvant* [TW] }\end{array}$ \\
\hline & C. Pathologic & \#7: Basic terms: complete respon*[TW] OR & C. Managed by & \#14: "Watchful Waiting"[Mesh] OR \\
\hline & complete & complete remission* $[$ TW $]$ & watch and wait & "Watch and wait"[TW] OR \\
\hline & response to & \#8: Additional terms to expand the search: & approach after & "Wait-and-see"[TW] OR \\
\hline & therapy: & completed respon*[TW] OR pathologic & therapy: \#14 & "Watch \& Wait"[TW] \\
\hline
\end{tabular}
respon*[TW] OR Clinical respon*[TW] OR "tumour regression grade" [TW] OR "tumor regression grade" $[T W] O R$ "tumour regression grades" $[T W] O R$ "tumor regression grades" $[T W]$ $O R$ viable[TW]

\begin{tabular}{|c|c|}
\hline $\mathrm{I}$ and $\mathrm{C}$ & $\begin{array}{l}\text { MRI or other } \\
\text { typical tests } \\
\text { (endoscopy, } \\
\text { endorectal } \\
\text { ultrasound, CT, } \\
\text { or PET): \#9 OR } \\
\text { \#10 OR \#11 OR } \\
\text { \#12 OR \#13 }\end{array}$ \\
\hline
\end{tabular}

\#9: Basic terms: Magnetic Resonance Imaging[Mesh] OR Magnetic Resonanc*[TW] OR MRI[TW] OR MRIs[TW] OR MR[TW]

\#10: Additional terms to expand the search: "diffusion-weighted"[TW] OR "DWI"[TW] OR "T2-weighted"[TW]

\#11: "Colonoscopy"[Mesh] OR colonoscop*[TW] OR Endoscop*[TW] OR Ultrasound*[TW] OR ultrasonograp*[TW] OR EUS[TW] OR Endosonography[Mesh] OR Endosonograp*[TW]

\#12: “Tomography, X-Ray Computed"[Mesh] OR CT[TI] OR Computed tomograp*[TW] OR computer assisted tomograp* [TW] OR computerised tomograp*[TW]

\#13: "Positron-Emission Tomography"[Mesh] OR "Positron-Emission"[TW] OR PET[TW]

0 Not applied, i.e., hand search of relevant articles Not applicable Others Written in English \#15: English[Lang]

Final search P AND (I and C) AND Others Written in English \#15: English[Lang] P AND 0thers Not applicable 


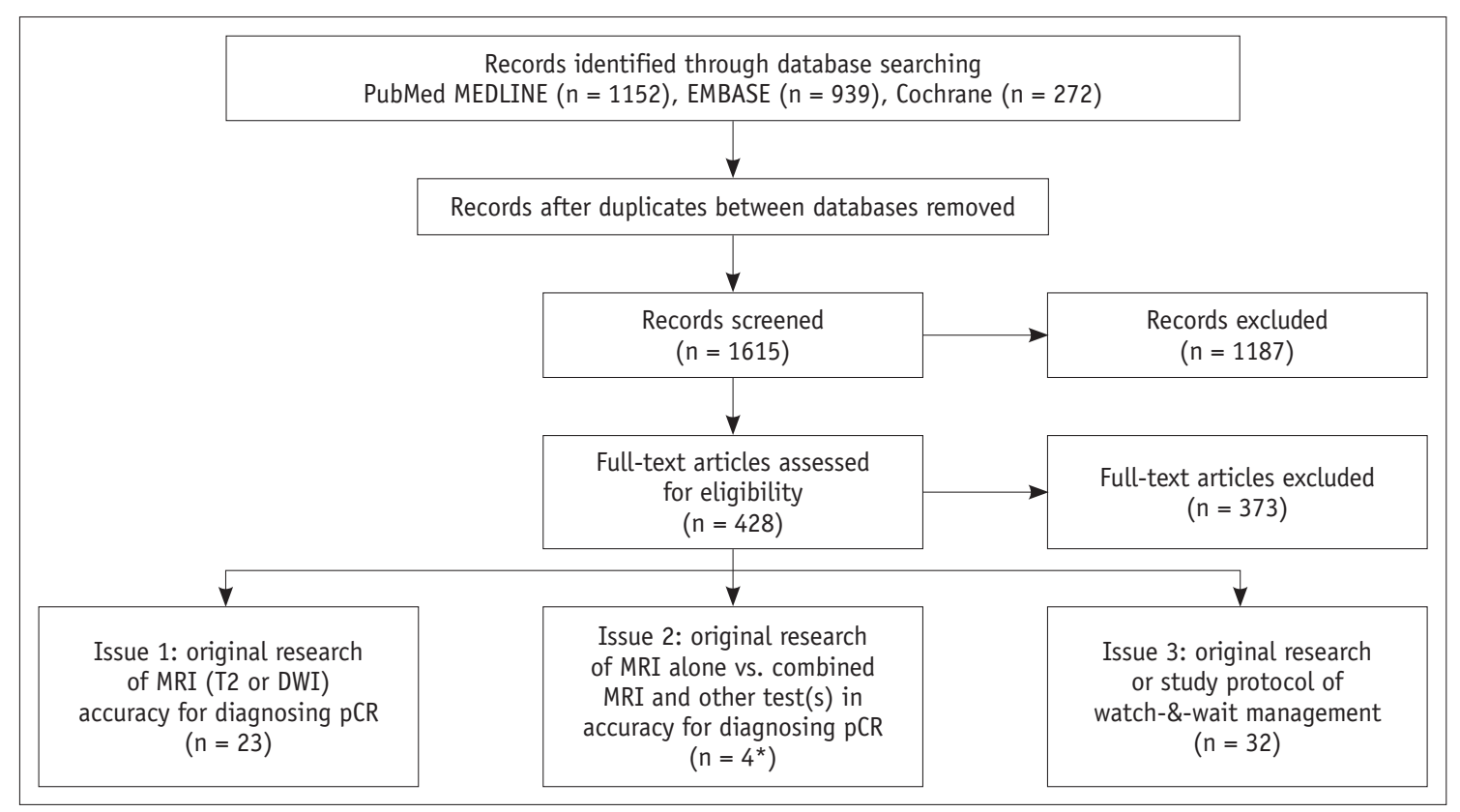

Fig. 1. Flow diagram of literature search. Four articles selected for issue 2 (asterisk) are also included in 23 articles selected for issue 1. DWI = diffusion-weighted imaging, MRI = magnetic resonance imaging, $\mathrm{pCR}=$ pathologic complete response, $\mathrm{T} 2=\mathrm{T} 2$-weighted imaging

consensus for any ambiguities. All the nine people who participated in the literature review were board-certified radiologists with expertise in the subject matters as well as in the systematic review of the literature.

\section{Issue 1: Sensitivity and Specificity of MRI (T2 or} DWI) for Diagnosing PCR and the Criteria for the MRI

\section{Diagnosis}

For this analysis, eligible articles were selected by further applying the following issue-specific criteria: 1) accurate, sufficient details to construct a diagnostic 2-by-2 table of visual interpretation of T2 or DWI and the reference standard findings for PCR (Fig. 2); 2) at least ten patients for both patients with $\mathrm{pCR}$ and those without $\mathrm{PCR} ; 3$ ) technical requirement for MRI according to the 2016 recommendation from the European Society of Gastrointestinal and Abdominal Radiology (ESGAR), including use of an external surface coil on a $1.5 \mathrm{~T}$ or $3 \mathrm{~T}$ systems and, in case of DWI, use of a high b-value of $\geq 800$ $\mathrm{sec} / \mathrm{mm}^{2}(16)$; and 4) MRI obtained after the completion of CRT. Articles not fulfilling any of these criteria were excluded. As shown in Figure 2, pCR instead of residual cancer was considered as the target condition to diagnose, and the sensitivity and specificity were defined accordingly. Studies that reported receiver operating characteristic (ROC) analysis alone without presenting any specific cutoff to use for the binary diagnosis were excluded. The exclusion was

\begin{tabular}{|c|c|c|}
\cline { 2 - 3 } & $\begin{array}{c}\text { Reference standard: } \\
\mathrm{pCR}\end{array}$ & $\begin{array}{c}\text { Reference standard: } \\
\text { not } \mathrm{pCR} \\
\text { (i.e., residual cancer) }\end{array}$ \\
\hline $\begin{array}{c}\text { Index test: } \\
\text { complete response }\end{array}$ & $\mathrm{a}$ & $\mathrm{c}$ \\
\hline $\begin{array}{c}\text { Index test: } \\
\text { not complete response }\end{array}$ & $\mathrm{b}$ & $\mathrm{d}$ \\
\hline \multicolumn{3}{|c|}{$\begin{array}{c}\text { Sensitivity for } \mathrm{pCR}=\mathrm{a} /(\mathrm{a}+\mathrm{b}) \\
\text { Specificity for } \mathrm{pCR}=\mathrm{d} /(\mathrm{c}+\mathrm{d})\end{array}$} \\
\hline
\end{tabular}

Fig. 2. Diagnostic 2-by-2 table for pCR.

because ROC analysis alone, unaccompanied by a suggestion of a specific cutoff, can only show a theoretical diagnostic performance over the entire range of possible cutoff values. Therefore, it cannot be directly translated into daily practice.

\section{Meta-Analysis of the Sensitivity and Specificity of T2, DWI, and Combined T2 and DWI for Diagnosing pCR}

One article may contain more than one set of the 2-by2 results (Fig. 2). Then, the data for meta-analysis were chosen as follows: the main result was considered when both the main result for the entire subjects and result(s) for the subgroup(s) were present; if one article presents parallel results for $>1$ independent patient groups, each was considered as a separate study; and in case of a multireader study or a study suggesting $>1$ discrete diagnostic 
criterion, the result of the reader or the diagnostic criterion that yielded the highest Youden index value was considered.

The presence of heterogeneity between studies concerning sensitivity and specificity was assessed using Higgins $\mathrm{I}^{2}$ statistics $(19,20)$. Heterogeneity by threshold effect was analyzed primarily by visual assessment of the coupled forest plots of sensitivity and specificity. It was further tested using the Spearman correlation coefficient between sensitivity and 1-specificity $(20,21)$. The summary sensitivity and specificity and their $95 \%$ confidence intervals (CIs) were obtained using a bivariate randomeffects model $(20,22)$. These analyses were performed separately for T2, DWI, and combined T2 and DWI.

Of the eligible studies, a subgroup of studies that reported sensitivity and specificity for pCR both for T2 and for combined T2 and DWI in the same group of patients were identified. T2 and combined T2 and DWI were compared regarding the sensitivity and specificity for $\mathrm{pCR}$ in this subgroup of studies using a joint-model bivariate meta-regression.

The statistical analyses were conducted using Stata version 15.1 (StataCorp LLC, College Station, TX, USA), with $p<0.05$ considered statistically significant.

\section{Systematic Review of the Criteria for the MRI Diagnosis of Complete Tumor Response}

The criteria for diagnosing complete tumor response on either T2 or DWI described in the studies identified were categorized, and the number of articles for each category was counted. The methods of combining the results of the two imaging methods were recorded for studies reporting the sensitivity and specificity of combined T2 and DWI.

Issue 2: Comparison of MRI alone (T2 with or without DWI) and MRI Combined with Other Test(s) Regarding Sensitivity and Specificity for $\mathrm{pCR}$

We considered endoscopy, endorectal ultrasound, and positron-emission tomography (PET, including PET, PET(TT, and PET-MR) as other tests used in combination with MRI. Reports of studies that evaluated the sensitivity and specificity for diagnosing pCR both for MRI alone and for MRI combined with any of these other tests in the same group of patients were identified. Otherwise, the article selection criteria were the same as those explained earlier in issue 1. MRI alone and MRI combined with other test(s) were compared regarding sensitivity and specificity for $\mathrm{PCR}$ using a joint-model bivariate meta-regression. Stata version
15.1 was used, with $p<0.05$ considered statistically significant.

Issue 3: Tests Used to Select Patients for the Watch-andWait Management

Articles that collected patients to offer the watch-andwait management after CRT for rectal cancer and mentioned the use of specific test(s) for the patient selection, for example, a clear mention of MRI, endoscopy, etc., instead of a vague description of "various imaging modalities," besides basic physician assessment and physical examination (such as digital rectal examination), were collected. Both original research studies and research protocols describing a plan for such a study were identified. The two types of articles were checked regarding any overlap, i.e., a publication of research that corresponds to a previously published protocol. Specific tests that were used to select patients for the watch-and-wait management, as described in the published articles, were summarized.

\section{RESULTS}

\section{Article Selection}

The article screening and selection processes are summarized in Figure 1. A total of 23 articles (23-45) were identified regarding issues 1 and 2, and a total of 32 articles were identified for issue $3(6,46-76)$.

Issue 1: Sensitivity and Specificity of MRI (T2 or DWI) for Diagnosing PCR and the Criteria for the MRI Diagnosis

Of the 23 eligible articles (23-45), 20 were reports of retrospective research studies, and three were prospective studies. They included a total of 40-514 patients (median, 103 patients); with 10-103 patients with pCR (median, 21 patients) and 29-411 patients (median, 83 patients) without pCR (i.e., residual tumor). There were 17 studies, five studies (a study by Cai et al. (25) was counted twice as it had separate results for two independent patient groups, each of which was considered separately for the metaanalysis), and eight studies that reported the sensitivity and specificity for diagnosing pCR for T2, DWI, and combined T2 and DWI, respectively.

\section{Meta-Analysis of the Sensitivity and Specificity of T2, DWI, and Combined T2 and DWI for Diagnosing pCR} The meta-analytic results of the 17 studies reporting the 


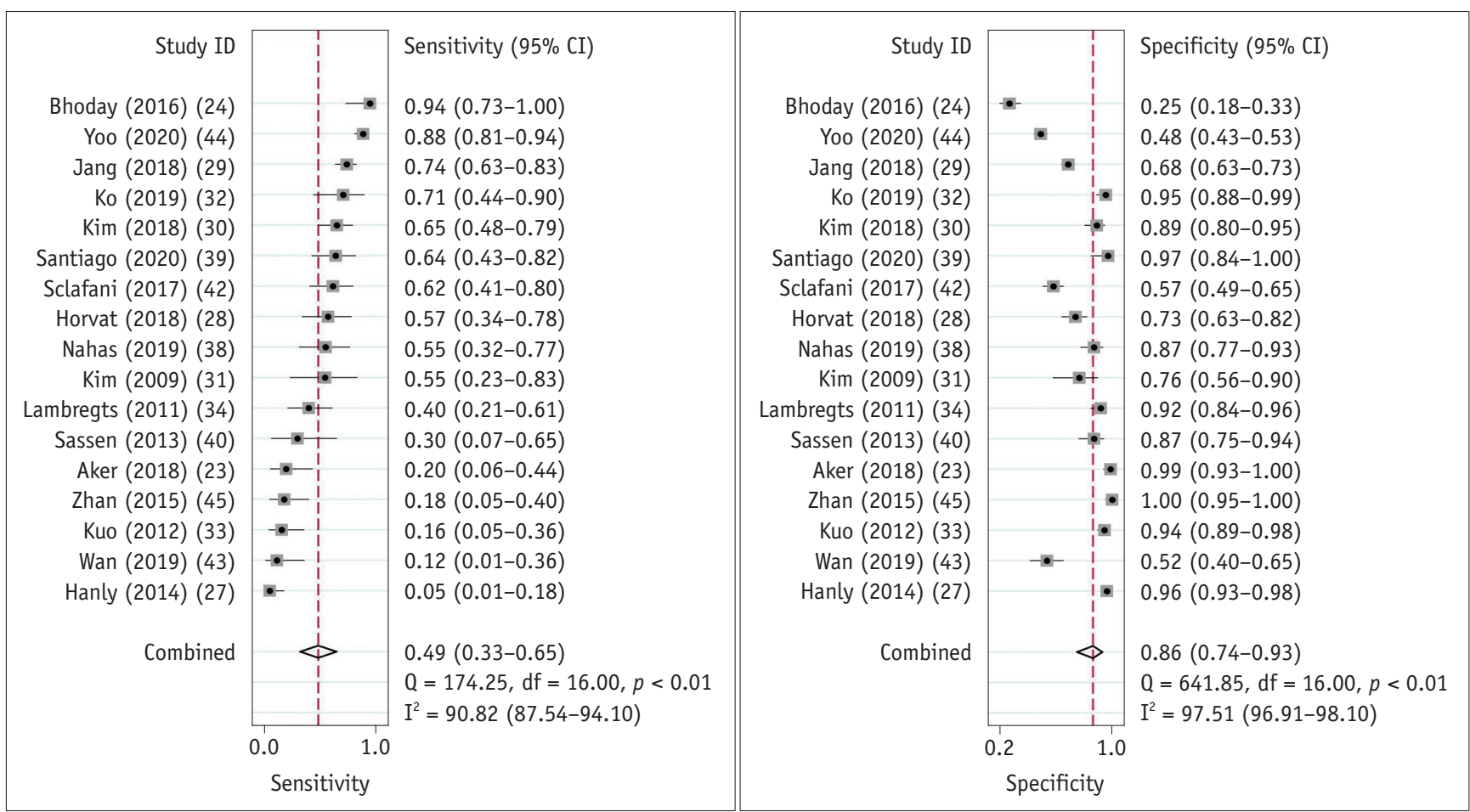

A

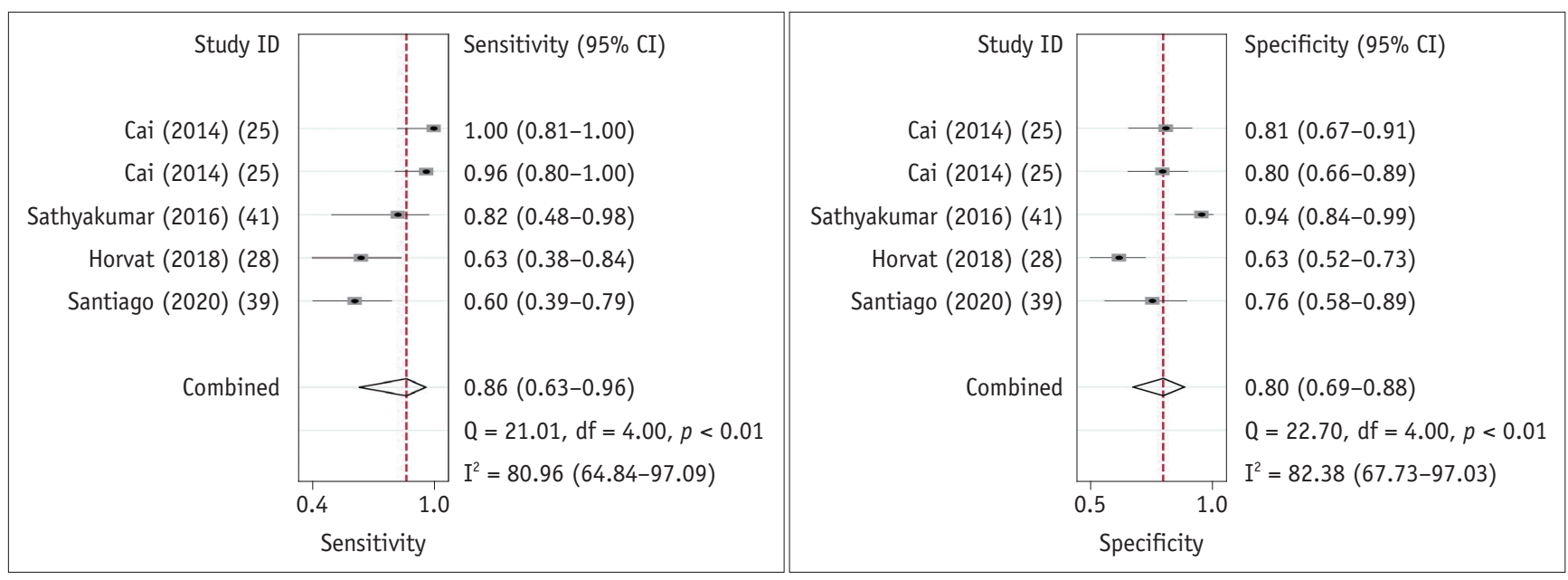

Fig. 3. Coupled forest plots of sensitivity and specificity of MRI for diagnosing PCR.

A. T2. B. DWI. Cai (2014) (25) is included twice as it contains separate results for two independent patient groups, each of which was considered separately for meta-analysis. $\mathrm{CI}=$ confidence interval

sensitivity and specificity of T2 for diagnosing pCR (23, $24,27-34,38-40,42-45)$ are summarized in Figure $3 \mathrm{~A}$ as coupled forest plots. There was a large study heterogeneity both for the sensitivity and the specificity $\left(\mathrm{I}^{2}=90.82\right.$ [95\% CI, 87.54-94.10] for sensitivity and $\mathrm{I}^{2}=97.51[95 \%$ CI, 96.91-98.10] for specificity). The coupled forest plots revealed a mild inverse relationship between sensitivity and specificity, although the Spearman's rho between sensitivity and 1-specificity was not statistically significant $(0.472$, $p=0.056)$. The summary sensitivity and specificity were 0.49 (95\% CI, 0.33-0.65) and 0.86 (95\% CI, 0.74-0.93), respectively.

The meta-analytic results of the five studies reporting the sensitivity and specificity of DWI for diagnosing PCR (25, $28,39,41)$ are summarized in Figure $3 B$ as coupled forest plots. There was a large study heterogeneity both for the sensitivity and the specificity $\left(\mathrm{I}^{2}=80.96\right.$ [95\% CI, 64.8497.09] for sensitivity and $\mathrm{I}^{2}=82.38[95 \% \mathrm{CI}, 67.73-97.03]$ 


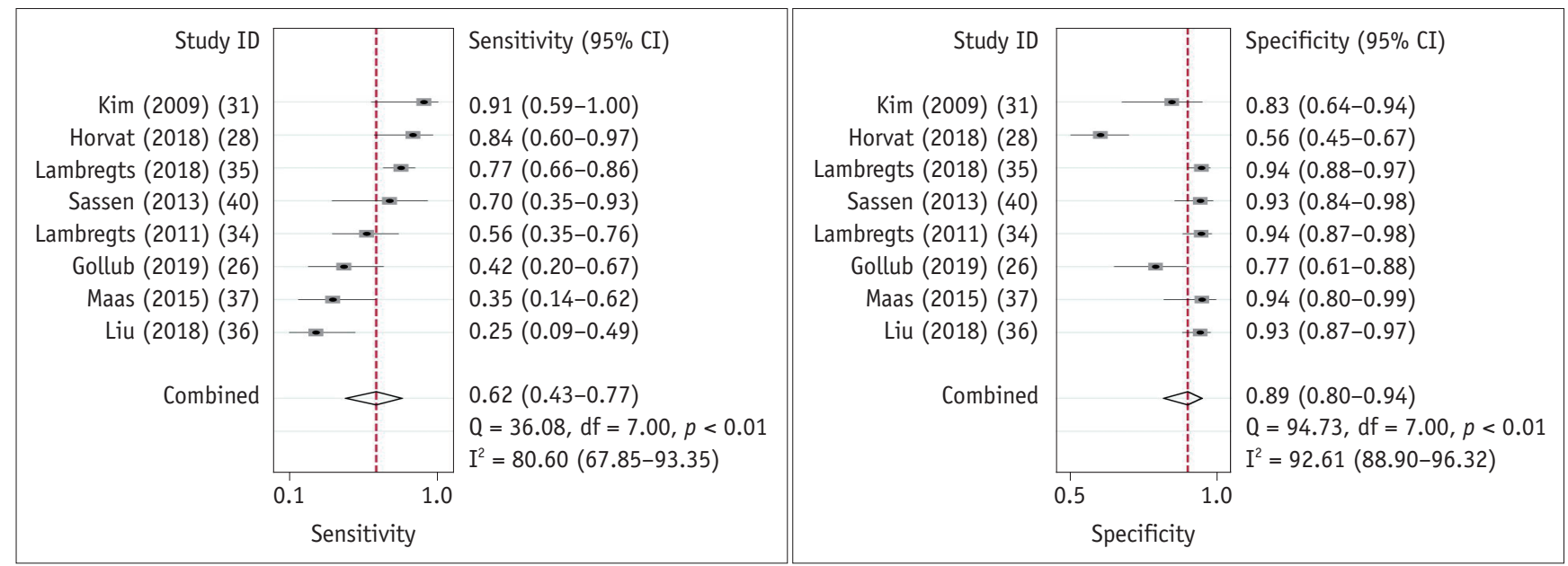

\section{C}

Fig. 3. Coupled forest plots of sensitivity and specificity of MRI for diagnosing pCR.

C. Combined T2 and DWI. CI = confidence interval

for specificity). The threshold effect was not apparent (Spearman's rho between sensitivity and 1-specificity = $-0.600, p=0.285)$. The summary sensitivity and specificity were 0.86 (95\% CI, 0.63-0.96) and 0.80 (95\% CI, $0.69-$ $0.88)$, respectively.

The meta-analytic results of the eight studies reporting the sensitivity and specificity of combined T2 and DWI for diagnosing $\mathrm{PCR}(26,28,31,34-37,40)$ are summarized in Figure $3 \mathrm{C}$ as coupled forest plots. There was a large study heterogeneity both for the sensitivity and the specificity $\left(\mathrm{I}^{2}=80.60\right.$ [95\% CI, 67.85-93.35] for sensitivity and $\mathrm{I}^{2}=$ 92.61 [95\% CI, 88.90-96.32] for specificity). The threshold effect was not apparent (Spearman's rho between sensitivity and 1-specificity $=0.333, p=0.420$ ). The summary sensitivity and specificity were 0.62 (95\% CI, 0.43-0.77) and 0.89 (95\% CI, 0.80-0.94), respectively.

Four studies reported the sensitivity and specificity for pCR both for T2 and for combined T2 and DWI in the same group of patients $(28,31,34,40)$. The details are provided in Table 2. None of the individual studies explicitly reported statistical comparisons regarding sensitivity and specificity between T2 and combined T2 and DWI. The meta-analytic comparison revealed a significant difference between the two imaging techniques $(p=0.01)$. According to the sample values alone reported in the individual studies (i.e., without regard to statistical comparison), three studies reported an increase in both sensitivity and specificity with combined T2 and DWI compared with T2 alone $(31,34,40)$.

\section{Systematic Review of the Criteria for the MRI Diagnosis of Complete Tumor Response}

The criteria for diagnosing complete tumor response on either T2 or DWI and the methods of combining the results of T2 and DWI, as reported in the 23 eligible articles (2345), are summarized in Table 3 . For the $\mathrm{T} 2$, most studies used the absence of visible tumor signal as the criteria. Meanwhile, the exact definitions and strictness for the absence of visible tumor varied among studies, ranging from complete normalization to hypointense thickening (i.e., dense fibrosis) of the wall in the tumor bed. For DWI, most articles adopted the absence of a hyperintense signal on high b-value $\left(\geq 800 \mathrm{sec} / \mathrm{mm}^{2}\right)$ DWI in the former tumor location. The methods of combining the results of $\mathrm{T} 2$ and DWI were obscure in half of the studies. Those studies that specifically reported the rules to combine T2 and DWI considered the absence of residual tumor on both $\mathrm{T} 2$ and DWI as complete tumor response or primarily followed T2 findings and referred to DWI when T2 findings were equivocal.

Issue 2: Comparison of MRI Alone (T2 with or without DWI) and MRI Combined with 0ther Test(s) Regarding Sensitivity and Specificity for $\mathrm{pCR}$

Four studies reported the sensitivity and specificity for $\mathrm{PCR}$ both for MRI alone and for MRI combined with other test(s) in the same group of patients $(32,33,36,37)$. The details are provided in Table 4. The meta-analytic comparison revealed a significant difference between MRI alone and MRI combined with other test(s) $(p=0.02)$. According to the sample values alone reported in the individual studies, 
Table 2. Studies Reporting Sensitivity and Specificity for Diagnosing PCR both for T2 and for Combined T2 and DWI in Same Group of Patients

\begin{tabular}{|c|c|c|c|c|c|c|}
\hline $\begin{array}{l}\text { First Author } \\
\text { (Year) }\end{array}$ & Study Type & MR Method & $\begin{array}{l}\text { Sensitivity, } \\
\% *\end{array}$ & $\begin{array}{l}\text { Specificity, } \\
\% *\end{array}$ & Comparative Result & $\begin{array}{c}\text { Method to Combine T2 } \\
\text { and DWI Results }\end{array}$ \\
\hline \multirow[t]{2}{*}{$\begin{array}{l}\text { Kim (2009) } \\
(31)\end{array}$} & \multirow[t]{2}{*}{ Retrospective } & $\mathrm{T} 2$ & $\begin{array}{c}54.5 \\
(6 / 11)\end{array}$ & $\begin{array}{c}75.9 \\
(22 / 29)\end{array}$ & \multirow{2}{*}{$\begin{array}{l}\text { Significantly higher overall } \\
\text { accuracy for combined T2 } \\
\text { and DWI compared with T2 } \\
\text { ( } p=0.0313 \text { by McNemar test) }\end{array}$} & \multirow{2}{*}{$\begin{array}{l}\text { T2 findings as primary results, } \\
\text { with DWI to override T2 when } \\
\text { T2 findings are equivocal or to } \\
\text { increase reader confidence if T2 } \\
\text { and DWI findings are consistent }\end{array}$} \\
\hline & & $\begin{array}{l}\text { Combined T2 } \\
\text { and DWI }\end{array}$ & $\begin{array}{c}90.9 \\
(10 / 11)\end{array}$ & $\begin{array}{c}82.8 \\
(24 / 29)\end{array}$ & & \\
\hline \multirow[t]{2}{*}{$\begin{array}{l}\text { Lambregts } \\
\text { (2011) (34) }\end{array}$} & \multirow[t]{2}{*}{ Retrospective } & T2 & $\begin{array}{c}40.0 \\
(10 / 25)\end{array}$ & $\begin{array}{c}91.6 \\
(87 / 95)\end{array}$ & \multirow{2}{*}{$\begin{array}{l}\text { No statistical comparisons } \\
\text { regarding binary } \\
\text { interpretations. Area under } \\
\text { ROC curve was } 0.8 \text { for } \\
\text { combined T2 and DWI and } \\
0.76 \text { for T2 }(p=0.39)\end{array}$} & \multirow[t]{2}{*}{ Obscure } \\
\hline & & $\begin{array}{l}\text { Combined T2 } \\
\text { and DWI }\end{array}$ & $\begin{array}{c}56.0 \\
(14 / 25)\end{array}$ & $\begin{array}{c}93.7 \\
(89 / 95)\end{array}$ & & \\
\hline \multirow[t]{2}{*}{$\begin{array}{l}\text { Sassen (2013) } \\
(40)\end{array}$} & \multirow[t]{2}{*}{ Retrospective } & $\mathrm{T} 2$ & $\begin{array}{c}30.0 \\
(3 / 10)\end{array}$ & $\begin{array}{c}86.7 \\
(52 / 60)\end{array}$ & \multirow{2}{*}{$\begin{array}{l}\text { No statistical comparisons } \\
\text { regarding binary } \\
\text { interpretations. Area under } \\
\text { ROC curve was } 0.89 \text { for } \\
\text { combined T2 and DWI and } \\
0.77 \text { for T2 }(p=0.005)\end{array}$} & \multirow[t]{2}{*}{ Obscure } \\
\hline & & $\begin{array}{c}\text { Combined T2 } \\
\text { and DWI }\end{array}$ & $\begin{array}{c}70.0 \\
(7 / 10)\end{array}$ & $\begin{array}{c}93.3 \\
(56 / 60)\end{array}$ & & \\
\hline \multirow[t]{2}{*}{$\begin{array}{l}\text { Horvat (2018) } \\
(28)\end{array}$} & \multirow[t]{2}{*}{ Retrospective } & T2 & $\begin{array}{c}57.1 \\
(12 / 21)\end{array}$ & $\begin{array}{c}73.1 \\
(68 / 93)\end{array}$ & \multirow[t]{2}{*}{ No statistical comparisons } & \multirow[t]{2}{*}{ Obscure $^{\dagger}$} \\
\hline & & $\begin{array}{l}\text { Combined T2 } \\
\text { and DWI }\end{array}$ & $\begin{array}{c}84.2 \\
(16 / 19)\end{array}$ & $\begin{array}{c}56.3 \\
(49 / 87)\end{array}$ & & \\
\hline \multirow[t]{2}{*}{$\begin{array}{l}\text { Meta-analytic } \\
\text { summary }\end{array}$} & \multirow[t]{2}{*}{ NA } & $\mathrm{T} 2$ & $\begin{array}{c}47 \\
(95 \% \mathrm{CI} \\
30-63)\end{array}$ & $\begin{array}{c}84 \\
(95 \% \mathrm{CI} \\
72-95)\end{array}$ & \multirow[t]{2}{*}{$\begin{array}{l}p=0.01 \text { from joint-model } \\
\text { bivariate meta-regression } \\
\text { analysis }\end{array}$} & \multirow[t]{2}{*}{ NA } \\
\hline & & $\begin{array}{l}\text { Combined T2 } \\
\text { and DWI }\end{array}$ & $\begin{array}{c}74 \\
(95 \% \mathrm{CI} \\
60-88)\end{array}$ & $\begin{array}{c}85 \\
(95 \% \mathrm{CI} \\
74-96)\end{array}$ & & \\
\hline
\end{tabular}

${ }^{*}$ Numbers in parentheses are number of patients unless specified otherwise, ${ }^{\dagger}$ Article states complete tumor response on MRI when both T2 and DWI were negative for residual tumor. However, reported results are more compatible with combined MRI result of complete tumor response when T2 or DWI was negative for residual tumor. CI $=$ confidence interval, DWI = diffusion-weighted imaging, $M R=$ magnetic resonance, $\mathrm{NA}=$ not applicable, $\mathrm{pCR}=$ pathologic complete response, $\mathrm{ROC}=$ receiver operating characteristic, $\mathrm{T} 2=\mathrm{T} 2$-weighted $\mathrm{imaging}$

three studies showed higher specificity but lower sensitivity for pCR when MRI was combined with other test(s) (32,

$33,36)$, whereas one study reported an increase in both sensitivity and specificity when endoscopy and digital rectal examination were also used combined with MRI (37).

Issue 3: Tests Used to Select Patients for the Watch-andWait Management

Twenty-nine original research articles $(6,48-65,67-76)$ and three reports of research protocols $(46,47,66)$ were eligible. There was no overlap between them. The details are summarized in Table 5. Almost all studies adopted MRI and endoscopy as the tests to select patients for the watchand-wait management despite some small variations among studies.

\section{DISCUSSION: KSAR GUIDE}

Sensitivity and Specificity of MRI for Diagnosing PCR

There is a limitation in interpreting the meta-analytic summary sensitivity and specificity of T2 or DWI for diagnosing $\mathrm{PCR}$ due to the large heterogeneity in the published results. Study heterogeneity is common for systematic review and meta-analysis of diagnostic test accuracy (77). Determining the specific causes for the heterogeneity is difficult because, in general, various factors are intertwined. Within the limitations, MRI using visual assessment of T2 overall had low sensitivity and moderately high specificity for diagnosing $\mathrm{pCR}$ after CRT for rectal cancer. Adding DWI to T2 seems beneficial as it increased the diagnostic performance to some extent. 
Table 3. Criteria for MRI Diagnosis of Complete Tumor Response

\begin{tabular}{|c|c|c|}
\hline MR Method & Criterion & Number of Articles* \\
\hline \multirow[t]{10}{*}{ T2 } & Visible tumor signal is absent. & \\
\hline & $\begin{array}{l}\text { - Normalization of wall in tumor bed; no detectable mass, nodular intermediate signal, or wall } \\
\text { thickening (with individual layers of wall identified again) }\end{array}$ & 4 \\
\hline & $\begin{array}{l}\text { - } \operatorname{mrTRG}^{\dagger} \text { : linear/crescentic thin scar in mucosa/submucosa or apparent normalization of wall in } \\
\text { tumor bed }\end{array}$ & 5 \\
\hline & $\begin{array}{l}\text { - Regular, hypointense scar in inner layer without bulging or breach by intermediate signal and } \\
\text { homogeneous intermediate signal in underlying layer of wall in tumor bed }\end{array}$ & 1 \\
\hline & - Normalization of wall or hypointense wall (with thickening) without intermediate signal in tumor bed & 5 \\
\hline & - $\operatorname{mrTRG1} 1-2^{\dagger}:$ mrTRG1 or dense fibrosis with no obvious residual tumor & 4 \\
\hline & Visible tumor signal may be present in small amount. & \\
\hline & - $\operatorname{mrTRG1} 13^{\dagger}:$ mrTRG1-2 or $>50 \%$ fibrosis or mucin and visible residual intermediate tumor signal & 1 \\
\hline & - Residual intermediate tumor signal in $\leq 25 \%$ of tumor bed & 1 \\
\hline & Obscure & 3 \\
\hline \multirow[t]{3}{*}{ DWI } & No hyperintense signal on high b-value $\left(\geq 800 \mathrm{sec} / \mathrm{mm}^{2}\right)$ DWI in tumor bed & 8 \\
\hline & Hyperintense signal in $\leq 25 \%$ in tumor bed & 1 \\
\hline & Obscure & 2 \\
\hline Combined & When both $\mathrm{T} 2$ and DWI are negative for residual tumor & 1 \\
\hline \multirow[t]{3}{*}{$\begin{array}{l}\text { T2 and } \\
\text { DWI }^{\ddagger}\end{array}$} & $\begin{array}{l}\text { When both T2 and DWI are negative for residual tumor, with DWI being decisive if T2 findings are } \\
\text { equivocal }\end{array}$ & 2 \\
\hline & $\begin{array}{l}\text { T2 findings as primary results, with DWI to override T2 when T2 findings are equivocal or DWI to increase } \\
\text { reader confidence if T2 and DWI findings are consistent }\end{array}$ & 1 \\
\hline & Obscure & 4 \\
\hline
\end{tabular}

${ }^{*}$ One article may present more than one criterion, ${ }^{\dagger} \mathrm{mrTRG}$ is magnetic resonance tumor regression grade system proposed by MERCURY study group (24). Descriptions for mrTRG categories are according to most recent relevant papers (9, 24, 29), ”Rules to combine T2 and DWI results.

The diagnostic performance of MRI was moderate despite the combined use of T2 and DWI, and the lack of visible residual tumor on these imaging examinations does not necessarily mean $\mathrm{pCR}$. This is primarily because of the pathologic nature of the tumor response to CRT (Fig. 4) (78). Rectal cancer is known to respond to CRT through fragmentation and shrinkage (78). Besides, a small minority of originally non-mucinous rectal cancers may develop mucin lakes $(8,78)$. This mucinous transformation is considered a good prognostic sign, like fibrosis, and should be distinguished from the primarily mucinous subtype that tends to show a poor response to CRT (8). Fragmentation, i.e., the destruction of the main tumor mass and formation of small nests of tumor cells, is reported to occur in about $40-80 \%$ of relevant cases and typically leaves microscopic tumor fragments that are below the resolution of imaging examinations (Figs. 5, 6) $(78,79)$. Consequently, if patients without visible residual tumor on MRI after CRT for rectal cancer are offered the watch-and-wait management, a careful regular surveillance for tumor regrowth is crucial.

\section{Interpretation of Complete Tumor Response on T2}

A noteworthy finding is the somewhat heterogeneous criteria adopted by studies to diagnose complete tumor response on T2. Despite mild diversity, most of them have the commonality of a remarkable decrease of the tumor to the absence of mass-like or nodular intermediate signals (which would be perceived on T2 as residual tumor areas) in the tumor bed. Post-CRT changes in rectal cancer, as seen on T2, as well as pathologically are more complex than the simple characterization of normalization, fibrosis (hypointense signal on T2), and residual tumor (intermediate signal on T2) $(8,80)$. Complete normalization of the wall on MRI in the former tumor location is rare (8). Additionally, post-CRT changes without a residual tumor tissue can create an intermediate signal that can mimic the intermediate signal of a residual tumor (80). Therefore, the heterogeneous criteria adopted by the published studies list the varied T2 appearances of post-CRT state without apparent residual cancer (Fig. 7, Supplementary Materials). The findings of (near) normalization of the wall and regular, thin, hypointense scaring in the luminal side with (near) 
Table 4. Studies Reporting Sensitivity and Specificity for Diagnosing PCR both for MRI Alone and for MRI Combined with 0ther Test(s) in Same Group of Patients

\begin{tabular}{|c|c|c|c|c|c|c|}
\hline $\begin{array}{c}\text { First Author } \\
\text { (Year) }\end{array}$ & Study Type & Method & $\begin{array}{c}\text { Sensitivity, } \\
\%^{*}\end{array}$ & $\begin{array}{c}\text { Specificity, } \\
\%^{*}\end{array}$ & Comparative Result & $\begin{array}{l}\text { Method to Combine Results } \\
\text { of MRI and Other Test(s) }\end{array}$ \\
\hline \multirow[t]{2}{*}{$\begin{array}{l}\text { Kuo (2012) } \\
\text { (33) }\end{array}$} & \multirow[t]{2}{*}{ Retrospective } & MRI (T2) & $\begin{array}{c}16.0 \\
(4 / 25)\end{array}$ & $\begin{array}{c}94.3 \\
(133 / 141)\end{array}$ & \multirow{2}{*}{$\begin{array}{l}\text { No meaningful } \\
\text { statistical comparisons } \\
\text { due to low statistical } \\
\text { power }\end{array}$} & \multirow{2}{*}{$\begin{array}{l}\text { Complete tumor response } \\
\text { if both MRI and other } \\
\text { tests are negative for } \\
\text { residual tumor }\end{array}$} \\
\hline & & $\begin{array}{l}\text { MRI combined with } \\
\text { endoscopy and routine } \\
\text { superficial re-biopsy }\end{array}$ & $\begin{array}{c}8.0 \\
(2 / 25)\end{array}$ & $\begin{array}{c}100 \\
(141 / 141)\end{array}$ & & \\
\hline \multirow[t]{2}{*}{$\begin{array}{l}\text { Maas (2015) } \\
(37)\end{array}$} & \multirow[t]{2}{*}{ Prospective } & $\begin{array}{l}\text { MRI (combined T2 and } \\
\text { DWI) }\end{array}$ & $\begin{array}{c}35.3 \\
(6 / 17)\end{array}$ & $\begin{array}{c}93.9 \\
(31 / 33)\end{array}$ & \multirow[t]{2}{*}{$\begin{array}{r}\text { No statistical } \\
\text { comparisons }\end{array}$} & \multirow[t]{2}{*}{ Obscure } \\
\hline & & $\begin{array}{l}\text { MRI combined with } \\
\text { endoscopy and digital } \\
\text { rectal examination }\end{array}$ & $\begin{array}{c}70.6 \\
(12 / 17)\end{array}$ & $\begin{array}{c}97.0 \\
(32 / 33)\end{array}$ & & \\
\hline \multirow[t]{2}{*}{$\begin{array}{l}\text { Liu (2018) } \\
\quad(36)\end{array}$} & \multirow[t]{2}{*}{ Prospective } & $\begin{array}{l}\text { MRI (combined T2 and } \\
\text { DWI) }\end{array}$ & $\begin{array}{l}25.0 \\
(5 / 20)\end{array}$ & $\begin{array}{c}93.3 \\
(97 / 104)\end{array}$ & \multirow[t]{2}{*}{$\begin{array}{l}\text { No statistical } \\
\text { comparisons }\end{array}$} & \multirow[t]{2}{*}{ Obscure } \\
\hline & & $\begin{array}{l}\text { MRI combined with } \\
\text { endoscopy }\end{array}$ & $\begin{array}{c}10.0 \\
(2 / 20)\end{array}$ & $\begin{array}{c}100 \\
(104 / 104)\end{array}$ & & \\
\hline \multirow[t]{2}{*}{$\begin{array}{l}\text { Ko (2019) } \\
\text { (32) }\end{array}$} & \multirow[t]{2}{*}{ Retrospective } & MRI (T2) & $\begin{array}{c}70.6 \\
(12 / 17)\end{array}$ & $\begin{array}{c}95.3 \\
(81 / 85)\end{array}$ & \multirow{2}{*}{$\begin{array}{l}\text { No significant difference } \\
\text { in sensitivity } \\
(p=0.250) \text { and } \\
\text { specificity }(p=1.000)\end{array}$} & \multirow[t]{2}{*}{ Obscure } \\
\hline & & $\begin{array}{l}\text { MRI combined with } \\
\text { endoscopy }\end{array}$ & $\begin{array}{c}52.9 \\
(9 / 17)\end{array}$ & $\begin{array}{c}96.5 \\
(82 / 85)\end{array}$ & & \\
\hline \multirow[t]{2}{*}{$\begin{array}{l}\text { Meta-analytic } \\
\text { summary }\end{array}$} & \multirow[t]{2}{*}{ NA } & MRI & $\begin{array}{c}34 \\
(95 \% \mathrm{CI}, \\
7-62)\end{array}$ & $\begin{array}{c}94 \\
(95 \% \mathrm{CI} \\
91-97)\end{array}$ & \multirow{2}{*}{$\begin{array}{l}p=0.02 \text { from } \\
\text { joint-model bivariate } \\
\text { meta-regression } \\
\text { analysis }\end{array}$} & \multirow[t]{2}{*}{ NA } \\
\hline & & $\begin{array}{l}\text { MRI combined with } \\
\text { other test(s) }\end{array}$ & $\begin{array}{c}29 \\
(95 \% \text { CI } \\
3-55)\end{array}$ & $\begin{array}{c}99 \\
(95 \% \mathrm{CI} \\
98-100)\end{array}$ & & \\
\hline
\end{tabular}

*Numbers in parentheses are number of patients unless specified otherwise.

normal-appearance or homogeneous intermediate signal in the underlying wall are reported to be less likely to harbor occult residual cancer compared to the finding of hypointense thickening of the wall $(39,81)$. Considering these factors, it would be desirable for the clinical reading of a post-CRT MRI to describe not only the absence vs. presence of visible residual tumor but also the specifics of the MRI findings interpreted as the lack of visible residual tumor.

\section{Interpretation of Complete Tumor Response on DWI}

The interpretation of complete tumor response on DWI was more uniform in the published studies as the absence of a hyperintense signal on high b-value DWI in the former tumor location. Nevertheless, the lack of anatomical details and the greater vulnerability to artifacts of DWI can introduce inaccuracy and variability in interpreting DWI according to the level of experience of the readers $(8,82)$. The readers should be particularly careful to avoid making false interpretations for T2 shine-through effects, a signal from a different location than the former tumor site, and artefactual signals from susceptibility artifacts $(8,82)$.

\section{Combining T2 and DWI}

Published studies suggest that combined use of T2 and DWI is better than using T2 alone to diagnose PCR. Nonetheless, the exact algorithm to combine the results of T2 and DWI was a bit obscure. If one places more emphasis on the oncologic outcome of the patients, it is reasonable to use DWI to exclude patients suspicious of remaining tumor after it was initially ruled out on T2. However, it is yet uncertain if a simple intersection of the two results in this manner, i.e., complete tumor response on MRI when both $\mathrm{T} 2$ and DWI are negative for residual tumor, is ideal as it would increase the specificity probably at the cost of some decrease in sensitivity for PCR (i.e., increased likelihood of sending patients with $\mathrm{pCR}$ for radical surgery). The studies that reported both increased sensitivity and 
Table 5. Tests Used to Select Patients for Watch-and-Wait Management

\begin{tabular}{|c|c|c|c|c|c|c|c|c|}
\hline \multirow{2}{*}{ First Author (Year) } & \multirow{2}{*}{ Article Type } & \multicolumn{7}{|c|}{ Test Used* $(+=$ Used $)$} \\
\hline & & MRI & Endoscopy & EUS & $\mathrm{CT}$ & CEA & PET & EUA \\
\hline Habr-Gama (1998) (50) & Original research & & + & + & + & + & & \\
\hline Lambregts (2011) (59) & Original research & + & + & + & & & & \\
\hline Maas (2011) (62) & Original research & + & + & & & & & \\
\hline Dalton (2012) (48) & Original research & + & & & & & & + \\
\hline Habr-Gama (2013) (52) & Original research & + & + & + & & & + & \\
\hline Habr-Gama (2014) (51) & Original research & + & + & + & + & & & \\
\hline Li (2015) (60) & Original research & + & + & + & + & & & \\
\hline Smith (2015) (71) & Original research & + & + & & & + & & \\
\hline Lai (2016) (58) & Original research & + & + & + & + & & & \\
\hline Martens (2016) (63) & Original research & + & + & & & & & \\
\hline Renehan (2016) (6) & Original research & + & + & & & & & \\
\hline Rupinski (2016) (67) & Original research & + & + & & & & & \\
\hline Sanchez Loria (2016) (68) & Original research & + & + & & & & & \\
\hline Habr-Gama (2017) (54) & Original research & + & + & & & & & \\
\hline Hupkens (2017) (57) & Original research & + & + & & & & & \\
\hline Hupkens (2018) (56) & Original research & + & + & & & & & \\
\hline Lin (2018) (61) & Original research & + & + & & + & & + & \\
\hline Oh (2018) (65) & Original research & + & + & + & + & + & + & \\
\hline São Julião (2018) (69) & Original research & + & + & + & & + & & \\
\hline Sposato (2018) (74) & Original research & + & + & & & & & \\
\hline Habr-Gama (2019) (53) & Original research & + & + & & & & & \\
\hline Habr-Gama (2019) (55) & Original research & + & + & + & + & + & & \\
\hline Nasir (2019) (64) & Original research & + & + & & & & & \\
\hline São Julião (2019) (70) & Original research & + & + & + & & + & & \\
\hline Smith (2019) (72) & Original research & & + & & & & & \\
\hline Spiegel (2019) (73) & Original research & + & + & & + & & & \\
\hline Strode (2019) (75) & Original research & + & + & + & + & & & \\
\hline Yeom (2019) (76) & Original research & + & & & & & & \\
\hline Dizdarevic (2020) (49) & Original research & + & + & & & & & \\
\hline Barina (2017) (46) & Study protocol ${ }^{\dagger}$ & + & + & & + & + & & \\
\hline Battersby (2017) (47) & Study protocol ${ }^{\dagger}$ & + & & & & & & \\
\hline Rombouts (2017) (66) & Study protocol ${ }^{\dagger}$ & + & + & & & & & \\
\hline
\end{tabular}

*Evaluations that belong to basic physician assessment and physical examination such as digital rectal examination are not included. PET includes PET, PET-CT, and PET-MR, ${ }^{\dagger}$ Corresponding research results have not been published yet. $\mathrm{CEA}=$ carcinoembryonic antigen, $\mathrm{EUA}=$ examination under anesthesia, EUS $=$ endorectal ultrasound

increased specificity for diagnosing $\mathrm{PCR}$ with the addition of DWI suggest that improved diagnostic performance without sacrificing any of both parameters is achievable $(31,34$, 40), likely by combining the two results in some obscure tailored manners. Therefore, further studies are needed to explicitly determine the optimal algorithms to combine T2 and DWI. Hence, all readers can use the two imaging methods together more reliably and more effectively.

\section{Combining MRI and other Tests}

One approach to deal with the limited accuracy of MRI in diagnosing PCR would be to combine it with other tests.
This systematic review shows that the combination of MRI and endoscopy is the approach that is most favored by the experts in the field. This is consistent with the statistics collected by the International Watch and Wait Database Consortium from 47 participating institutions in 15 countries (7). Published studies show that false diagnosis of pCR in patients who had a residual tumor could be reduced by combining MRI with other tests. However, it was at the cost of reduced sensitivity for $p C R$. These results are expected with the approach of deciding a complete tumor response if both MRI and other tests are all negative for the residual tumor. This approach would be appropriate if 


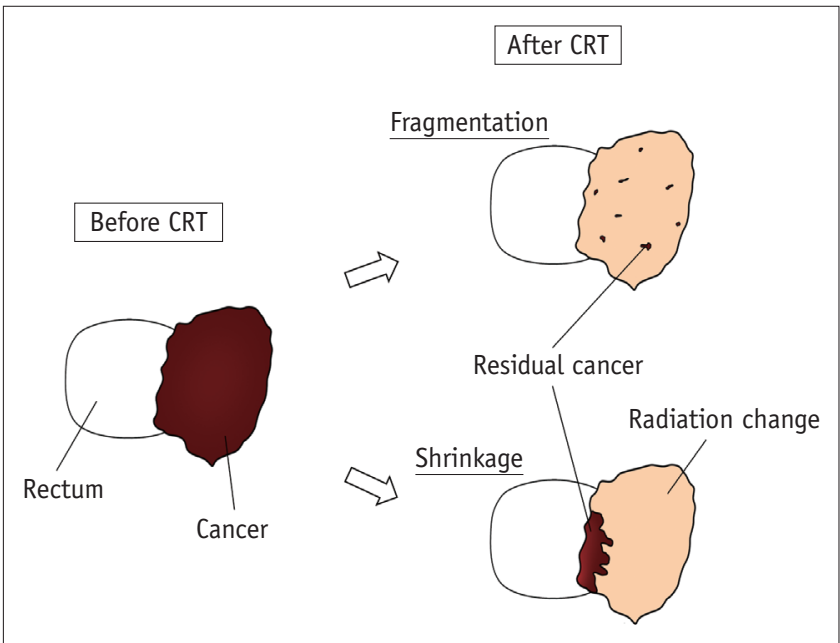

Fig. 4. Schematic representation of patterns of rectal cancer response to CRT. Fragmentation is destruction of main tumor mass and formation of small nests of tumor cells, whereas shrinkage is tumor reduction in direction of mucosa. CRT = chemoradiation therapy

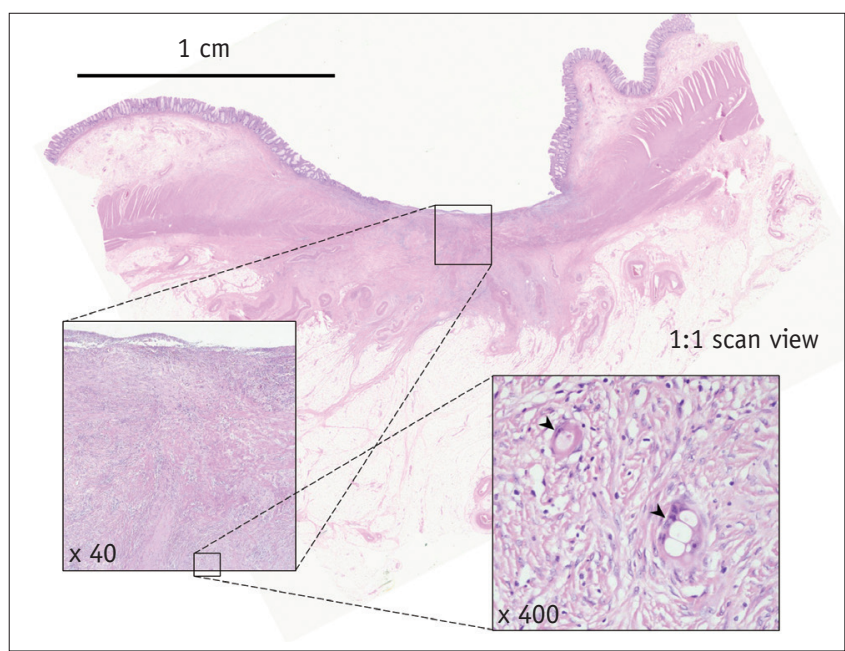

Fig. 5. Microscopic size of residual tumor in case of near total regression after CRT for rectal cancer. Tiny nests of residual cancer cells are marked by arrowheads in most magnified (x 400) view. H\&E stain (Courtesy of Dr. Hee Sang Hwang in Department of Pathology, Asan Medical Center, University of Ulsan College of Medicine, Seoul, Korea). $\mathrm{H} \& \mathrm{E}=$ hematoxylin and eosin

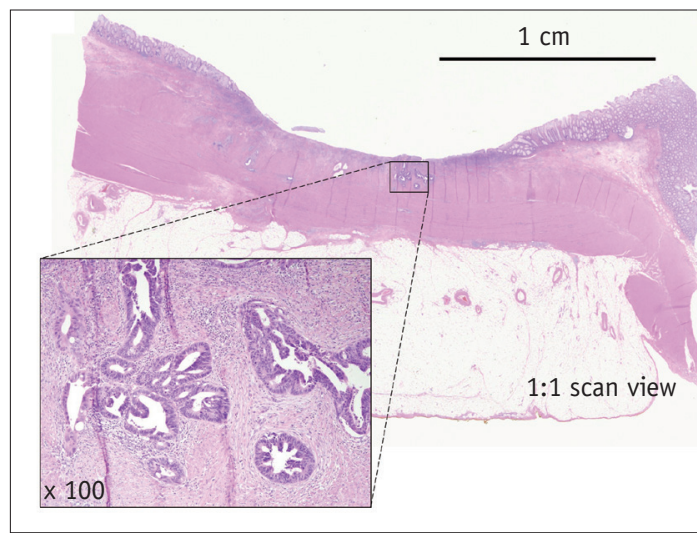

A

Fig. 6. Microscopic size of residual tumor in case of moderate regression after CRT for rectal cancer.

A. Small glands of residual cancer cells are noted in tumor bed. H\&E stain (Courtesy of Dr. Hee Sang Hwang in Department of Pathology, Asan Medical Center, University of Ulsan College of Medicine, Seoul, Korea). B. Residual tumor is still too small to be seen on MRI, albeit larger than that of near total regression as shown in Figure. 5. Therefore, wall in tumor bed (arrowheads) appears essentially normal on MRI after CRT.

oncologic outcome and safety are the concern. However, compared with the use of a single test, this approach would deprive an opportunity for less invasive management in more patients who have achieved pCR. There are yet limited data to confirm if and how a multi-test approach could increase the performance for diagnosing $\mathrm{pCR}$ and avoid sacrificing the sensitivity or the specificity. Therefore, further investigations are needed to determine the most effective strategy to combine different tests to select patients for the watch-and-wait management.

\section{Issues Uncovered}

Although this guide focuses on the interpretation of complete tumor response on MRI with respect to the primary tumor, the entire clinical decision of complete tumor response requires the same evaluation for nodal metastasis and tumor deposits. To our knowledge, there is not enough data in the literature to draw an evidence synthesis on the evaluation for nodal metastasis and tumor deposits. Nevertheless, ESGAR has recently proposed as an expert consensus opinion that all nodes with a short-axis diameter $<5 \mathrm{~mm}$ and $\geq 5 \mathrm{~mm}$ on post-CRT MRI should be considered benign and suspicious, respectively (16).

\section{Summary}

This systematic review and meta-analysis provide an 


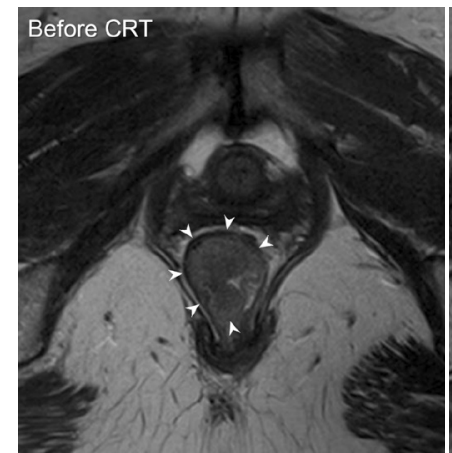

A

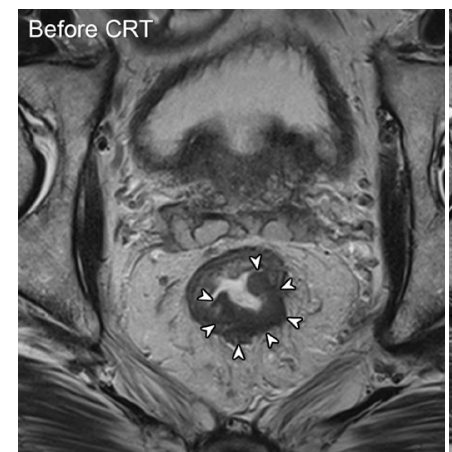

C
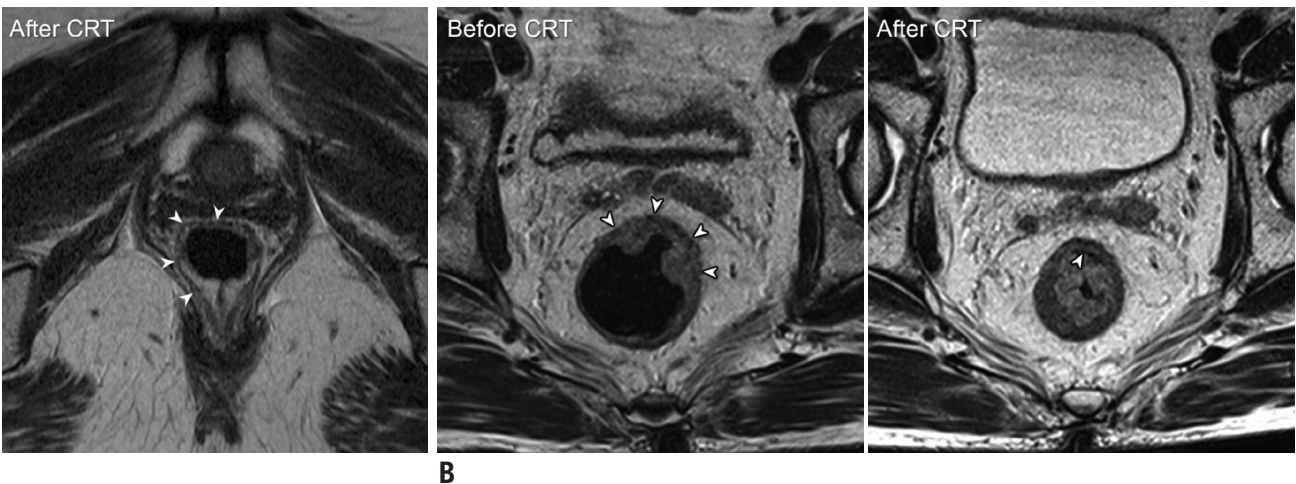

B
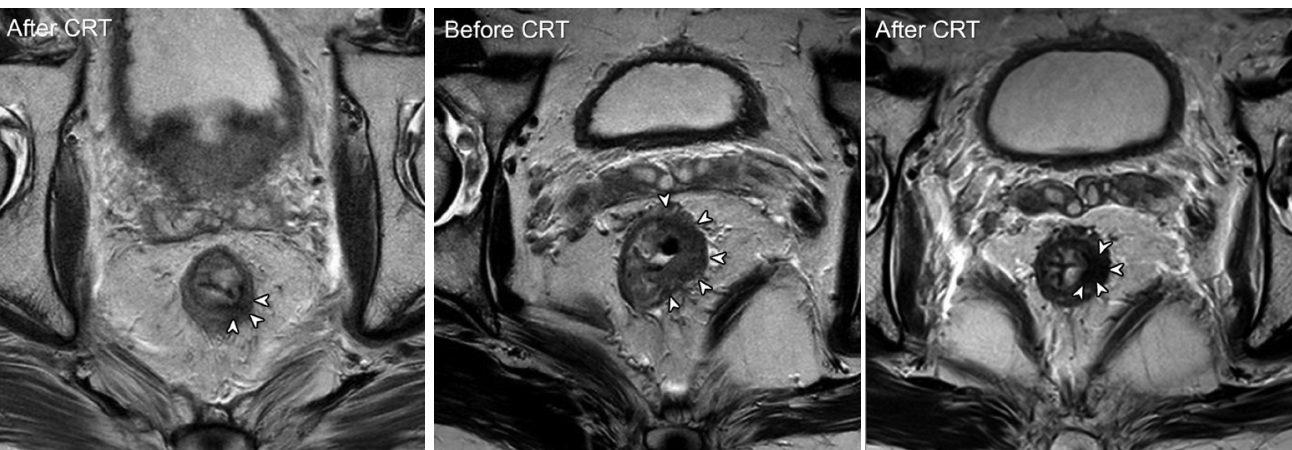

D

Fig. 7. Exemplary cases of complete tumor response, i.e., no visible residual tumor on T2 after CRT.

A. Complete normalization of wall in tumor bed (arrowheads) after CRT. Pathology was total regression. B. Regular, thin, hypointense scar in luminal side and normalization of underlying wall in tumor bed (arrowheads) after CRT. Pathology was total regression. C. Regular, thin, hypointense scar in luminal side and a homogeneous, intermediate signal of underlying wall with mild thickening in tumor bed (arrowheads) after CRT. Pathology was total regression. D. Dense, hypointense thickening of wall in tumor bed (arrowheads) after CRT. Pathology was total regression.

evidence-based practical guide for MRI assessment of complete tumor response after CRT for rectal cancer. Within the limitation of considerable heterogeneity in the published results, with visual assessment, combined T2 and DWI seems more favorable than T2 alone in diagnosing PCR after CRT for rectal cancer and showed modest summary sensitivity and moderately high summary specificity. The criteria for complete tumor response on T2 may include (near) normalization of the wall; regular, thin, hypointense scar in the luminal side with (near) normal-appearance or homogeneous intermediate signal in the underlying wall; and hypointense thickening of the wall in the former tumor location. The criterion for complete tumor response on DWI should be the absence of a hyperintense signal on high $b$-value DWI in the former tumor location. The optimal algorithms to combine the results of T2 and DWI have yet to be defined more explicitly. The use of MRI and endoscopy was the most utilized means to select patients for the watch-and-wait management. However, the evidence is yet scarce regarding if a multi-test approach is beneficial and what combinations of the tests are most effective.

\section{Supplementary Materials}

The Data Supplement is available with this article at https://doi.org/10.3348/kjr.2020.0483.

\section{Conflicts of Interest}

The authors have no potential conflicts of interest to disclose.

\section{ORCID iDs}

\section{Seong Ho Park}

https://orcid.org/0000-0002-1257-8315

Seung Hyun Cho

https://orcid.org/0000-0001-7617-7302

Sang Hyun Choi

https://orcid.org/0000-0002-6898-6617

Jong Keon Jang

https://orcid.org/0000-0002-2938-6635

Min Ju Kim

https://orcid.org/0000-0002-5431-6321 


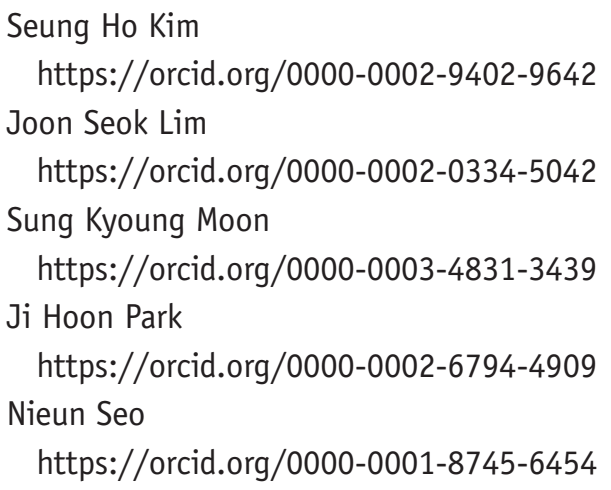

\section{REFERENCES}

1. Smith FM, Cresswell K, Myint AS, Renehan AG. Is "watch-andwait" after chemoradiotherapy safe in patients with rectal cancer? BMJ 2018;363:k4472

2. Maas $M$, Nelemans PJ, Valentini $V$, Das $P$, Rödel C, Kuo LJ, et al. Long-term outcome in patients with a pathological complete response after chemoradiation for rectal cancer: a pooled analysis of individual patient data. Lancet Oncol 2010;11:835-844

3. Dattani M, Heald RJ, Goussous G, Broadhurst J, São Julião GP, Habr-Gama A, et al. Oncological and survival outcomes in watch and wait patients with a clinical complete response after neoadjuvant chemoradiotherapy for rectal cancer: a systematic review and pooled analysis. Ann Surg 2018;268:955-967

4. Dossa F, Chesney TR, Acuna SA, Baxter NN. A watch-and-wait approach for locally advanced rectal cancer after a clinical complete response following neoadjuvant chemoradiation: a systematic review and meta-analysis. Lancet Gastroenterol Hepatol 2017;2:501-513

5. Chadi SA, Malcomson L, Ensor J, Riley RD, Vaccaro CA, Rossi $\mathrm{GL}$, et al. Factors affecting local regrowth after watch and wait for patients with a clinical complete response following chemoradiotherapy in rectal cancer (InterCoRe consortium): an individual participant data meta-analysis. Lancet Gastroenterol Hepatol 2018;3:825-836

6. Renehan AG, Malcomson L, Emsley R, Gollins S, Maw A, Myint $A S$, et al. Watch-and-wait approach versus surgical resection after chemoradiotherapy for patients with rectal cancer (the OnCoRe project): a propensity-score matched cohort analysis. Lancet Oncol 2016;17:174-183

7. van der Valk MJM, Hilling DE, Bastiaannet E, MeershoekKlein Kranenbarg E, Beets GL, Figueiredo NL, et al. Long-term outcomes of clinical complete responders after neoadjuvant treatment for rectal cancer in the International Watch \& Wait Database (IWWD): an international multicentre registry study. Lancet 2018;391:2537-2545

8. Lambregts DMJ, Boellaard TN, Beets-Tan RGH. Response evaluation after neoadjuvant treatment for rectal cancer using modern MR imaging: a pictorial review. Insights Imaging
2019;10:15

9. Seo N, Kim H, Cho MS, Lim JS. Response assessment with MRI after chemoradiotherapy in rectal cancer: current evidences. Korean J Radiol 2019;20:1003-1018

10. Gollub MJ, Arya S, Beets-Tan RG, dePrisco G, Gonen M, Jhaveri $\mathrm{K}$, et al. Use of magnetic resonance imaging in rectal cancer patients: Society of Abdominal Radiology (SAR) rectal cancer disease-focused panel (DFP) recommendations 2017. Abdom Radiol (NY) 2018;43:2893-2902

11. Cho SH, Cho YS, Choi IY, Ha HI, Huh J, Hur BY, et al.; KSAR Study Group for Rectal Cancer. Essential items for structured reporting of rectal cancer MRI: 2016 consensus recommendation from the Korean Society of Abdominal Radiology. Korean J Radiol 2017;18:132-151

12. Kennedy ED, Milot L, Fruitman M, Al-Sukhni E, Heine G, Schmocker S, et al. Development and implementation of a synoptic MRI report for preoperative staging of rectal cancer on a population-based level. Dis Colon Rectum 2014;57:700708

13. Tudyka V, Blomqvist L, Beets-Tan RG, Boelens PG, Valentini $V$, van de Velde $C J$, et al. EURECCA consensus conference highlights about colon \& rectal cancer multidisciplinary management: the radiology experts review. Eur J Surg Oncol 2014; $40: 469-475$

14. Beets-Tan RG, Lambregts DM, Maas M, Bipat S, Barbaro $B$, Caseiro-Alves $F$, et al. Magnetic resonance imaging for the clinical management of rectal cancer patients: recommendations from the 2012 European Society of Gastrointestinal and Abdominal Radiology (ESGAR) consensus meeting. Eur Radiol 2013;23:2522-2531

15. Taylor F, Mangat N, Swift IR, Brown G. Proforma-based reporting in rectal cancer. Cancer Imaging 2010;10 Spec no A:S142-S150

16. Beets-Tan RGH, Lambregts DMJ, Maas M, Bipat S, Barbaro B, Curvo-Semedo $L$, et al. Magnetic resonance imaging for clinical management of rectal cancer: updated recommendations from the 2016 European Society of Gastrointestinal and Abdominal Radiology (ESGAR) consensus meeting. Eur Radiol 2018;28:1465-1475

17. Bilgili MY. Reproductibility of apparent diffusion coefficients measurements in diffusion-weighted MRI of the abdomen with different b values. Eur J Radiol 2012;81:2066-2068

18. Kim KW, Lee J, Choi SH, Huh J, Park SH. Systematic review and meta-analysis of studies evaluating diagnostic test accuracy: a practical review for clinical researchers-Part I. General guidance and tips. Korean J Radiol 2015;16:11751187

19. Higgins JP, Thompson SG, Deeks JJ, Altman DG. Measuring inconsistency in meta-analyses. BMJ 2003;327:557-560

20. Lee J, Kim KW, Choi SH, Huh J, Park SH. Systematic review and meta-analysis of studies evaluating diagnostic test accuracy: a practical review for clinical researchers-Part II. Statistical methods of meta-analysis. Korean J Radiol 2015;16:1188-1196 
21. Devillé WL, Buntinx F, Bouter LM, Montori VM, de Vet HC, van der Windt DA, et al. Conducting systematic reviews of diagnostic studies: didactic guidelines. BMC Med Res Methodol 2002;2:9

22. Reitsma JB, Glas AS, Rutjes AW, Scholten RJ, Bossuyt $\mathrm{PM}$, Zwinderman AH. Bivariate analysis of sensitivity and specificity produces informative summary measures in diagnostic reviews. J Clin Epidemiol 2005;58:982-990

23. Aker M, Boone D, Chandramohan A, Sizer B, Motson R, Arulampalam T. Diagnostic accuracy of MRI in assessing tumor regression and identifying complete response in patients with locally advanced rectal cancer after neoadjuvant treatment. Abdom Radiol (NY) 2018;43:3213-3219

24. Bhoday J, Smith F, Siddiqui MR, Balyasnikova S, Swift RI, Perez $\mathrm{R}$, et al. Magnetic resonance tumor regression grade and residual mucosal abnormality as predictors for pathological complete response in rectal cancer postneoadjuvant chemoradiotherapy. Dis Colon Rectum 2016;59:925-933

25. Cai PQ, Wu YP, An X, Qiu X, Kong LH, Liu GC, et al. Simple measurements on diffusion-weighted MR imaging for assessment of complete response to neoadjuvant chemoradiotherapy in locally advanced rectal cancer. Eur Radiol 2014;24:2962-2970

26. Gollub MJ, Blazic I, Felder S, Knezevic A, Gonen M, GarciaAguilar J, et al. Value of adding dynamic contrast-enhanced MRI visual assessment to conventional MRI and clinical assessment in the diagnosis of complete tumour response to chemoradiotherapy for rectal cancer. Eur Radiol 2019;29:11041113

27. Hanly AM, Ryan EM, Rogers AC, McNamara DA, Madoff RD, Winter DC, et al. Multicenter Evaluation of Rectal cancer ReImaging p0st Neoadjuvant (MERRION) therapy. Ann Surg 2014;259:723-727

28. Horvat N, Veeraraghavan H, Khan M, Blazic I, Zheng J, Capanu $M$, et al. MR imaging of rectal cancer: radiomics analysis to assess treatment response after neoadjuvant therapy. Radiology 2018;287:833-843

29. Jang JK, Lee JL, Park SH, Park HJ, Park IJ, Kim JH, et al. Magnetic resonance tumour regression grade and pathological correlates in patients with rectal cancer. Br J Surg 2018;105:1671-1679

30. Kim S, Han K, Seo N, Kim HJ, Kim MJ, Koom WS, et al. T2weighted signal intensity-selected volumetry for prediction of pathological complete response after preoperative chemoradiotherapy in locally advanced rectal cancer. Eur Radiol 2018;28:5231-5240

31. Kim SH, Lee JM, Hong SH, Kim GH, Lee JY, Han JK, et al. Locally advanced rectal cancer: added value of diffusionweighted MR imaging in the evaluation of tumor response to neoadjuvant chemo- and radiation therapy. Radiology 2009;253:116-125

32. Ko HM, Choi YH, Lee JE, Lee KH, Kim JY, Kim JS. Combination assessment of clinical complete response of patients with rectal cancer following chemoradiotherapy with endoscopy and magnetic resonance imaging. Ann Coloproctol 2019;35:202-208

33. Kuo LJ, Chiou JF, Tai CJ, Chang CC, Kung CH, Lin SE, et al. Can we predict pathologic complete response before surgery for locally advanced rectal cancer treated with preoperative chemoradiation therapy? Int J Colorectal Dis 2012;27:613-621

34. Lambregts DM, Vandecaveye V, Barbaro B, Bakers FC, Lambrecht M, Maas M, et al. Diffusion-weighted MRI for selection of complete responders after chemoradiation for locally advanced rectal cancer: a multicenter study. Ann Surg Oncol 2011;18:2224-2231

35. Lambregts DMJ, Delli Pizzi A, Lahaye MJ, van Griethuysen JJM, Maas M, Beets GL, et al. A pattern-based approach combining tumor morphology on MRI with distinct signal patterns on diffusion-weighted imaging to assess response of rectal tumors after chemoradiotherapy. Dis Colon Rectum 2018;61:328-337

36. Liu S, Zhong GX, Zhou WX, Xue HD, Pan WD, Xu L, et al. Can endorectal ultrasound, MRI, and mucosa integrity accurately predict the complete response for mid-low rectal cancer after preoperative chemoradiation? A prospective observational study from a single medical center. Dis Colon Rectum 2018;61:903-910

37. Maas M, Lambregts DM, Nelemans PJ, Heijnen LA, Martens $\mathrm{MH}$, Leijtens JW, et al. Assessment of clinical complete response after chemoradiation for rectal cancer with digital rectal examination, endoscopy, and MRI: selection for organsaving treatment. Ann Surg Oncol 2015;22:3873-3880

38. Nahas SC, Nahas CSR, Cama GM, de Azambuja RL, Horvat $\mathrm{N}$, Marques CFS, et al. Diagnostic performance of magnetic resonance to assess treatment response after neoadjuvant therapy in patients with locally advanced rectal cancer. Abdom Radiol (NY) 2019;44:3632-3640

39. Santiago I, Barata M, Figueiredo N, Parés 0, Henriques V, Galzerano A, et al. The split scar sign as an indicator of sustained complete response after neoadjuvant therapy in rectal cancer. Eur Radiol 2020;30:224-238

40. Sassen S, de Booij M, Sosef M, Berendsen R, Lammering G, Clarijs $R$, et al. Locally advanced rectal cancer: is diffusion weighted MRI helpful for the identification of complete responders (ypTONO) after neoadjuvant chemoradiation therapy? Eur Radiol 2013;23:3440-3449

41. Sathyakumar K, Chandramohan A, Masih D, Jesudasan MR, Pulimood A, Eapen A. Best MRI predictors of complete response to neoadjuvant chemoradiation in locally advanced rectal cancer. Br J Radiol 2016;89:20150328

42. Sclafani F, Brown G, Cunningham D, Wotherspoon A, Mendes LST, Balyasnikova S, et al. Comparison between MRI and pathology in the assessment of tumour regression grade in rectal cancer. Br J Cancer 2017;117:1478-1485

43. Wan L, Zhang C, Zhao Q, Meng Y, Zou S, Yang Y, et al. Developing a prediction model based on MRI for pathological complete response after neoadjuvant chemoradiotherapy in locally advanced rectal cancer. Abdom Radiol (NY) 
2019;44:2978-2987

44. Yoo GS, Park HC, Yu JI, Choi DH, Cho WK, Park YS, et al. Carcinoembryonic antigen improves the performance of magnetic resonance imaging in the prediction of pathologic response after neoadjuvant chemoradiation for patients with rectal cancer. Cancer Res Treat 2020;52:446-454

45. Zhan S, Wang X, Huang X, Zhu H. Magnetic resonance imaging in restaging rectal cancer after neoadjuvant chemoradiotherapy. J BUON 2015;20:62-67

46. Barina A, De Paoli A, Delrio P, Guerrieri M, Muratore A, Bianco $\mathrm{F}$, et al. Rectal sparing approach after preoperative radioand/or chemotherapy (RESARCH) in patients with rectal cancer: a multicentre observational study. Tech Coloproctol 2017;21:633-640

47. Battersby NJ, Dattani M, Rao S, Cunningham D, Tait D, Adams $R$, et al. A rectal cancer feasibility study with an embedded phase III trial design assessing magnetic resonance tumour regression grade ( $\mathrm{mrTRG}$ ) as a novel biomarker to stratify management by good and poor response to chemoradiotherapy (TRIGGER): study protocol for a randomised controlled trial. Trials 2017;18:394

48. Dalton RS, Velineni R, Osborne ME, Thomas R, Harries S, Gee $A S$, et al. A single-centre experience of chemoradiotherapy for rectal cancer: is there potential for nonoperative management? Colorectal Dis 2012;14:567-571

49. Dizdarevic E, Frøstrup Hansen T, Pløen J, Henrik Jensen L, Lindebjerg J, Rafaelsen S, et al. Long-term patient-reported outcomes after high-dose chemoradiation therapy for nonsurgical management of distal rectal cancer. Int $\mathrm{J}$ Radiat Oncol Biol Phys 2020;106:556-563

50. Habr-Gama A, de Souza PM, Ribeiro U Jr, Nadalin W, Gansl $\mathrm{R}$, Sousa $\mathrm{AH} \mathrm{Jr}$, et al. Low rectal cancer: impact of radiation and chemotherapy on surgical treatment. Dis Colon Rectum 1998;41:1087-1096

51. Habr-Gama A, Gama-Rodrigues J, São Julião GP, Proscurshim I, Sabbagh C, Lynn PB, et al. Local recurrence after complete clinical response and watch and wait in rectal cancer after neoadjuvant chemoradiation: impact of salvage therapy on local disease control. Int J Radiat Oncol Biol Phys 2014;88:822-828

52. Habr-Gama A, Sabbaga J, Gama-Rodrigues J, São Julião GP, Proscurshim I, Bailão Aguilar P, et al. Watch and wait approach following extended neoadjuvant chemoradiation for distal rectal cancer: are we getting closer to anal cancer management? Dis Colon Rectum 2013;56:1109-1117

53. Habr-Gama A, São Julião GP, Fernandez LM, Vailati BB, Andrade A, Araújo SEA, et al. Achieving a complete clinical response after neoadjuvant chemoradiation that does not require surgical resection: it may take longer than you think! Dis Colon Rectum 2019;62:802-808

54. Habr-Gama A, São Julião GP, Gama-Rodrigues J, Vailati BB, Ortega C, Fernandez LM, et al. Baseline T classification predicts early tumor regrowth after nonoperative management in distal rectal cancer after extended neoadjuvant chemoradiation and initial complete clinical response. Dis Colon Rectum 2017;60:586-594

55. Habr-Gama A, São Julião GP, Vailati BB, Fernandez LM, Ortega $C D$, Figueiredo $N$, et al. Organ preservation among patients with clinically node-positive rectal cancer: is it really more dangerous? Dis Colon Rectum 2019;62:675-683

56. Hupkens BJP, Maas M, Martens MH, van der Sande ME, Lambregts DMJ, Breukink S0, et al. Organ preservation in rectal cancer after chemoradiation: should we extend the observation period in patients with a clinical near-complete response? Ann Surg Oncol 2018;25:197-203

57. Hupkens BJP, Martens MH, Stoot JH, Berbee M, Melenhorst J, Beets-Tan RG, et al. Quality of life in rectal cancer patients after chemoradiation: watch-and-wait policy versus standard resection-A matched-controlled study. Dis Colon Rectum 2017;60:1032-1040

58. Lai CL, Lai MJ, Wu CC, Jao SW, Hsiao CW. Rectal cancer with complete clinical response after neoadjuvant chemoradiotherapy, surgery, or "watch and wait". Int J Colorectal Dis 2016;31:413-419

59. Lambregts DM, Maas M, Bakers FC, Cappendijk VC, Lammering $\mathrm{G}$, Beets $\mathrm{GL}$, et al. Long-term follow-up features on rectal MRI during a wait-and-see approach after a clinical complete response in patients with rectal cancer treated with chemoradiotherapy. Dis Colon Rectum 2011;54:1521-1528

60. Li J, Liu H, Yin J, Liu S, Hu J, Du F, et al. Wait-and-see or radical surgery for rectal cancer patients with a clinical complete response after neoadjuvant chemoradiotherapy: a cohort study. Oncotarget 2015;6:42354-42361

61. Lin GP, Lee KD, Wang JY, Chen JS, Chiang CJ, Yeh CY. Status for clinically complete remission rectal cancer after concomitant chemo-radiotherapy in Taiwan. Asian J Surg 2018;41:203-209

62. Maas M, Beets-Tan RG, Lambregts DM, Lammering G, Nelemans PJ, Engelen SM, et al. Wait-and-see policy for clinical complete responders after chemoradiation for rectal cancer. $J$ Clin Oncol 2011;29:4633-4640

63. Martens MH, Maas M, Heijnen LA, Lambregts DM, Leijtens JW, Stassen LP, et al. Long-term outcome of an organ preservation program after neoadjuvant treatment for rectal cancer. $\mathrm{J}$ Natl Cancer Inst 2016;108. pii: djw171

64. Nasir I, Fernandez L, Vieira P, Parés 0, Santiago I, CastilloMartin $M$, et al. Salvage surgery for local regrowths in watch \& wait-Are we harming our patients by deferring the surgery? Eur J Surg Oncol 2019;45:1559-1566

65. Oh BY, Huh JW, Lee WY, Park YA, Cho YB, Yun SH, et al. Are we predicting disease progress of the rectal cancer patients without surgery after neoadjuvant chemoradiotherapy? Cancer Res Treat 2018;50:634-645

66. Rombouts AJM, Al-Najami I, Abbott NL, Appelt A, Baatrup G, Bach $S$, et al. Can we Save the rectum by watchful waiting or TransAnal microsurgery following (chemo) Radiotherapy versus Total mesorectal excision for early REctal Cancer (STAR-TREC study)?: protocol for a multicentre, randomised feasibility 
study. BMJ Open 2017;7:e019474

67. Rupinski M, Szczepkowski M, Malinowska M, Mroz A, Pietrzak $L$, Wyrwicz $L$, et al. Watch and wait policy after preoperative radiotherapy for rectal cancer; management of residual lesions that appear clinically benign. Eur J Surg Oncol 2016;42:288296

68. Sanchez Loria F, Iseas S, O'Connor JM, Pairola A, Chacon M, Mendez $G$, et al. Non-surgical management of rectal cancer. Series of 68 cases, long follow up in two leading centres in Argentina. Dig Liver Dis 2016;48:1372-1377

69. São Julião GP, Habr-Gama A, Vailati BB, Aguilar PB, Sabbaga $J$, Araújo SEA, et al. Is neoadjuvant chemoradiation with dose-escalation and consolidation chemotherapy sufficient to increase surgery-free and distant metastases-free survival in baseline cT3 rectal cancer? Eur J Surg Oncol 2018;44:93-99

70. São Julião GP, Karagkounis G, Fernandez LM, Habr-Gama A, Vailati BB, Dattani $M$, et al. Conditional survival in patients with rectal cancer and complete clinical response managed by watch and wait after chemoradiation: recurrence risk over time. Ann Surg 2019 Mar 26 [Epub]. https://doi.org/10.1097/ SLA.0000000000003286

71. Smith FM, Rao C, Oliva Perez R, Bujko K, Athanasiou T, HabrGama $A$, et al. Avoiding radical surgery improves early survival in elderly patients with rectal cancer, demonstrating complete clinical response after neoadjuvant therapy: results of a decision-analytic model. Dis Colon Rectum 2015;58:159-171

72. Smith JJ, Strombom P, Chow OS, Roxburgh CS, Lynn P, Eaton A, et al. Assessment of a watch-and-wait strategy for rectal cancer in patients with a complete response after neoadjuvant therapy. JAMA Oncol 2019;5:e185896

73. Spiegel DY, Boyer MJ, Hong JC, Williams CD, Kelley MJ, Moore $\mathrm{H}$, et al. Long-term clinical outcomes of nonoperative management with chemoradiotherapy for locally advanced rectal cancer in the veterans health administration. Int J Radiat Oncol Biol Phys 2019;103:565-573

74. Sposato LA, Lam Y, Karapetis C, Vatandoust S, Roy A, Hakendorf $\mathrm{P}$, et al. Observation of "complete clinical response" in rectal cancer after neoadjuvant chemoradiation: the Flinders experience. Asia Pac J Clin Oncol 2018;14:439445

75. Strode M, Shah R, Boland PM, Francescutti VA, Mangieri CW, Attwood K, et al. Nonoperative management after neoadjuvant therapy for rectal cancer: a single institution experience over 5 years. Surg Oncol 2019;28:116-120

76. Yeom SS, Lee SY, Kim CH, Kim YJ, Nam TK, Kim HR. Nonoperative treatment outcome for rectal cancer patient with clinical complete response after neoadjuvant chemoradiotherapy. Asian J Surg 2019;42:823-831

77. Suh CH, Park SH. Successful publication of systematic review and meta-analysis of studies evaluating diagnostic test accuracy. Korean J Radiol 2016;17:5-6

78. Nagtegaal ID, Glynne-Jones R. How to measure tumour response in rectal cancer? An explanation of discrepancies and suggestions for improvement. Cancer Treat Rev 2020;84:101964

79. Smith FM, Wiland H, Mace A, Pai RK, Kalady MF. Depth and lateral spread of microscopic residual rectal cancer after neoadjuvant chemoradiation: implications for treatment decisions. Colorectal Dis 2014;16:610-615

80. Jia X, Zhang Y, Wang Y, Feng C, Shen D, Ye Y, et al. MRI for restaging locally advanced rectal cancer: detailed analysis of discrepancies with the pathologic reference standard. AJR Am J Roentgenol 2019;213:1081-1090

81. Jang JK, Choi SH, Park SH, Kim KW, Kim HJ, Lee JS, et al. MR tumor regression grade for pathological complete response in rectal cancer post neoadjuvant chemoradiotherapy: a systematic review and meta-analysis for accuracy. Eur Radiol 2020;30:2312-2323

82. Lambregts DMJ, van Heeswijk MM, Delli Pizzi A, van Elderen SGC, Andrade L, Peters NHGM, et al. Diffusion-weighted MRI to assess response to chemoradiotherapy in rectal cancer: main interpretation pitfalls and their use for teaching. Eur Radiol 2017;27:4445-4454 